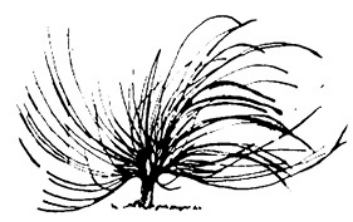

\title{
Language Teaching Methods: There is Nothing New Under the Sun, or Is There? ${ }^{1}$
}

\author{
Juan Pablo Zúñiga Vargas ${ }^{2}$ \\ Universidad de Costa Rica \\ San José, Costa Rica \\ juanpablo.zunigavargas@ucr.ac.cr
}

\begin{abstract}
This essay intends to problematize the possible direction that the field of language teaching will follow in the XXI century. For this purpose, nine methodological parameters for conceptualizing every language teaching method will be described, the impossibility of designating the best method will be considered, the concept of the post method condition and its ten macro strategies for language teaching will be discussed along with the challenges for its implementation, a minimalist proposal for language teaching will be referred to, and the current phenomenon of textbook-defined practice will be analyzed.
\end{abstract}

Keywords: languages, teaching, methods, pedagogy, postmethod condition, future

\section{(C) $(1) \Theta \Theta$}

Recibido: 23 de octubre de 2015-Aprobado: 4 de diciembre de 2015 https://doi.org/10.15359/rep.10-2.3.eng

1 This is an English translation of an essay first published in Spanish. The original Spanish version can be accessed at https://doi.org/10.15359/rep.10-2.3.

2 Professor of English for other majors, University of Costa Rica. Professor of pedagogy and educational research, Universidad Nacional, Costa Rica. He holds a Master's Degree in English Teaching as a Foreign Language and a Bachelor's Degree in English both from the University of Costa Rica. 


\begin{abstract}
Resumen
Este ensayo tiene como objetivo problematizar la posible dirección que seguirá el campo de la enseñanza de idiomas en el siglo XXI. Para tal fin, se describirán nueve parámetros metodológicos para la conceptualización de todo método para la enseñanza de idiomas, se reflexionará sobre la imposibilidad de designar el mejor método para la enseñanza de idiomas, se discutirá el concepto de la condición post métodos y sus diez macro estrategias para la enseñanza de idiomas junto con los desafíos para su puesta en práctica, se hará referencia a una propuesta minimalista para la enseñanza de idiomas y finalmente se analizará el fenómeno actual de la práctica definida por el libro de texto.
\end{abstract}

Palabras clave: métodos, enseñanza, idiomas, pedagogía, condición post métodos, futuro

\title{
Introduction
}

This essay's main purpose is to problematize the possible direction that the discipline of language teaching will follow in the $21^{\text {st }}$ century as well as describe what can (not) be new in this field of knowledge. Before engaging in such a discussion, it is important to make a basic clarification: In this essay, the word method will be used in a general way to refer to both language teaching methods and approaches without any attempts to generate controversy or debates about the epistemological differences between both these concepts.

Having made this initial clarification, the organization of this essay will be described in turn. First, a series of dimensions for language teaching will be analyzed, all of which can be applicable to all existing and future methods. Later, I will reflect on the difficulty or impossibility to appoint the best language teaching method. The post-method condition, along with some contemporary methodological recommendations will also be analyzed in an attempt to elucidate the possible paths to follow in the field of language teaching in the $21^{\text {st }}$ century. The main challenges faced in this emergent paradigm, a minimalist proposal for language teaching, and the current phenomenon of textbook-defined practice will also be described. It is expected, therefore, that the reflections and conclusions reached in this paper are of help to experienced and beginner language teachers who wish to (re)examine their current practice from a critical viewpoint seeking professional growth. 


\section{The Nine Dimensions of Language Teaching Methods}

In any language teacher training program, it is common for at least one of the courses in the courses on the syllabus to have to do with language teaching methods as its focus. This purpose of this course, however, is not always that clear as will be argued next. In a few cases, this course's goal can be for pre-service language teachers to know about the development of the discipline or for them to enrich their future professional practice by studying different methods and combining their various elements (strategies, techniques, and others) while teaching. Nonetheless, such theoretical study may be but a mere intellectual exercise with few pragmatic applications in language teachers' professional practice.

It is also common for the books or anthologies used in these courses to have a chronological organization in terms of the historical period in which the methods to be studied originated. Such thematic organization may imply that the discipline of language teaching was once in the dark, and it is until very recent that it walks towards the light. Still, this idea might be mistaken as suggested by Kumaravadivelu (2003), when considering that there is a great deal of theoretical overlapping in eleven methods described in two of the most commonly used books in language teaching courses and by Thornbury (2010), who proposed nine dimensions to conceptualize all language teaching methods. As aptly put by Thornbury (2010), the development of language teaching has not been linear; rather, it has been a spiral in which the same dimensions have been used differently to make sense of the different language teaching methods proposed. At this moment, it is relevant to point out that these dimensions must not be seen as dichotomies or sets of opposing notions but as spectra of possibilities within the field of language teaching. Thus, each method would be oriented towards the right of left end of this continuum according to its specific conceptualization. Each of these dimensions will be described in turn.

\section{Dimension 1: Language}

Each method presupposes a view about the nature of language (See Figure 1). Language can be seen as a set of rules (grammatical, morphological, phonological, among others), and learning and using it would consist of mastering such rules. In another sense, it can be inferred that language can be more of a social phenomenon, in which learning and using it are dependent upon its ultimate purpose: communication. 
Figure 1. The Nature of Language
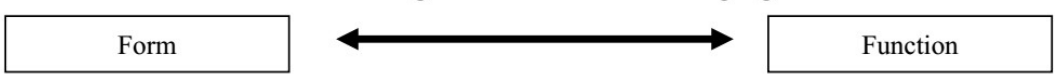

Note: Adapted from Thornbury (2010)

\section{Dimension 2: Learning}

The different language teaching methods take a cognitive or experiential perspective with regard to learning (See Figure 2). Learning a new language can then be seen as a merely analytical process of discovering rules and principles inductively or deductively. Notwithstanding, learning a language in other methods is something more experiential; one has to experience the language (live it) for learning to happen.

Figure 2. The Nature of Learning
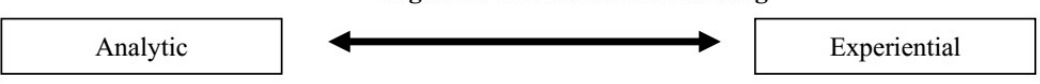

Note: Adapted from Thornbury (2010)

\section{Dimension 3: The Ultimate Purpose of Learning a Language}

There are methods for which the purpose of learning a language is engaging in a mental or personal-growth exercise. Having learned a language means being able to use it with impeccable grammar and pronunciation. Other methods, however, advocate for developing language's main reason for being: the need to communicate with others (See Figure 3). Without this basic need, no language would be possible. These views will consequently affect to a great extent the activities to be done in the classroom.

Figure 3. The Goal of Learning a Language
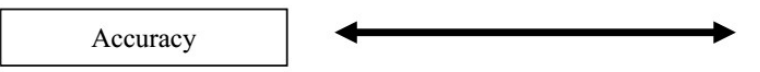

Communication

Note: Adapted from Thornbury (2010) 


\section{Dimension 4: Organization of a Language Course}

In terms of the organization of contents in a language course, in general, the syllabus can be arranged with a holistic or specific view of language (See Figure 4). An integrated course sees language as a system composed by different parts, which are all important for learning and ultimately acquiring it. There are other courses in which it is necessary and even more practical to separate language in its macro-skills (listening, speaking, reading, and writing) or in its micro-skills (grammar and pronunciation, for example) for students to grow linguistically by focusing on one skill at a time.

Figure 4. The Organizing Principle of a Language Course

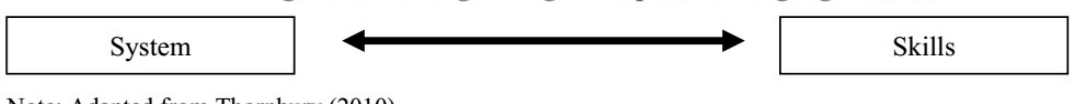

Note: Adapted from Thornbury (2010)

\section{Dimension 5: The Curriculum}

Within the realm of curriculum, a language course can be independent or be part of a greater structure (See Figure 5). In a language course that is segregated from the rest of the curriculum, topics of interest are studied whose primordial purpose is learning a language. On the other hand, if a language course is integrated in the school curriculum, students may learn about other subjects (history, science, mathematics, to mention a few). Thus, the purpose of such a language course is both to learn the language and grow personally and professionally by covering various topics. This integration model can be found in bilingual schools.

Figure 5. The Language Learning Curriculum

Segregated

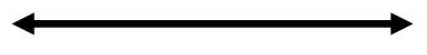

Integrated

Note: Adapted from Thornbury (2010) 


\section{Dimension 6: The Learner and the Materials}

Not all the language teaching methods proposed have provided and explicit vision about what role the language learner and the materials should play in a course. However, it is possible to identify two main roles in this regard (See Figure 6). Some methods have conceived learners as eminently cognitive beings, whose challenges and tasks to learn a new language are merely mental. Therefore, the materials to be used in a course with this perspective are to assist students in these intellectual exercises. Other methods see students as whole human beings provided with an affective sphere, which can be stimulated to achieve meaningful learning. Thus, the materials designed within this paradigm must help students manage their affective filter in one way or another.

Figure 6. The Role of the Learner and the Language Materials

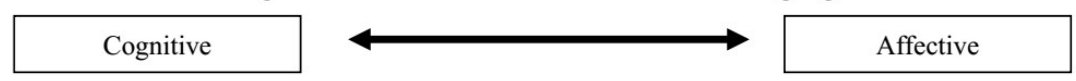

Note: Adapted from Thornbury (2010)

\section{Dimension 7: The Language Teacher}

The role played by the language teacher has been conceptualized from two main ambits, transmissive and dialogical (See Figure 7). Traditionally, the teacher has been seen as an almost unquestionable authority figure, whose duty is to transmit knowledge unidirectionally. More contemporary visions, however, have proposed that the teacher can have a more dialogical role, and teaching-learning processes may be more horizontal. In other words, the teacher does not need to know everything; the teacher is human, and both students and teacher can learn from one another.

Figure 7. The Role of the Language Teacher

Transmissive

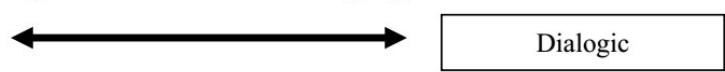

Note: Adapted from Thornbury (2010) 


\section{Dimension 8: The Language Learning Process}

In language teaching-learning processes, two main paradigms have been employed. Certain methods advocate for teaching students language rules explicitly for them to use them later by means of sentence-writing or pronunciation/phonetics exercises, while other methods recommend that students be guided in a process of selfdiscovery of linguistic rules and principles (See Figure 8). With regard to this dimension, experience seems to suggest that induction is more effective. Nonetheless, deduction should also be encouraged in the classroom since it is impossible to learn everything in a controlled environment; in real life, it will be necessary to face the unknown.

Figure 8. The Paradigm of the Language Learning Process

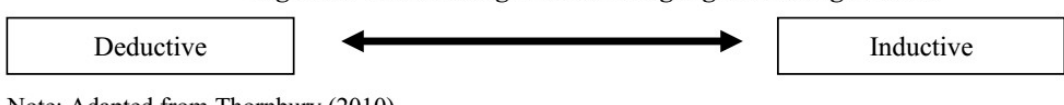

Note: Adapted from Thornbury (2010)

\section{Dimension 9: The Medium of Instruction for Language Teaching}

Different methods have suggested which language should be used most often in the classroom, be it the mother tongue or the target language (See Figure 9). For this reason, the Grammar-Translation Method resorts to translation as its main teaching technique. On the other hand, the Direct Method banned translation and focused exclusively on the use of the target language. Either of these ends entails strengths and weaknesses, so the language teacher must find the most appropriate moments to move to the left or right on this continuum.

Figure 9. Main Medium of Instruction in the Language Classroom

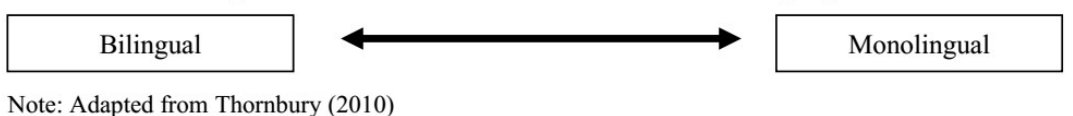


As said previously, no language teaching method (existing or to come) is necessarily new or authentic; instead, each method is a different permutation of all (or most) of the nine dimensions proposed by Thornbury (2010). Thornbury (2010) also stated that these nine dimensions may have methodological implications at the moment of planning a lesson for a language course. The different spectra of possibility found in each dimension can be adapted at the language teacher's convenience. In this sense, a simple comparison can be proposed: Each dimension can be seen as the faders in a stereo graphic equalizer. According to the students' needs and teaching context, the "sound" settings for each lesson can be adapted by moving towards the left or right on the spectrum in order to obtain the most learning gains from the teaching-learning experiences in the language course. Consequently, if certain implicit and explicit elements found in language teaching methods lead us to the conclusion that no method is truly authentic, thinking of which method could be the best is an even greater problem as will be argued in the following paragraphs.

\section{The Dilemma of Appointing the Best Method}

In teacher education courses in which different language teaching methods are studied, there is a recurrent question among students, "What is the best method?" This is a complex question since it can have no answer as well as multiple answers. Let us consider the following hypothetical example: In which teaching situation would the best results be obtained, in a course in which the "best" method is used by an unskillful teacher or in a course in which a "bad" method is followed by a passionate teacher? Since the last century, Prabhu (1990) came to the conclusion that there is no answer to the question of which method is best for various reasons that will be explained next.

\section{The Context Determines the Best Methodology}

In any teaching and learning process, the socio-economic and socio-educational contexts will always be different, and each language teaching method was conceived to be put into practice in a generic, ideal context. A combination of motivational, experiential, attitudinal, aptitude, economic, philosophical, curricular, cultural factors (to name a few) will directly affect the way teaching and 
learning happen. This means, then, that the choice of language teaching methods (or methodologies) has to be critical and flexible with the aim of responding to the diverse characteristics that shape each educational context. This way, the best language teaching method will be able to be chosen. One cannot think in a reductionist way and expect that the very same language teaching method works well in any educational contexts.

\section{Each Method Is Valid in Its Own Way}

Diverse methods have emerged and disappeared in the history of language teaching, and some have been more popular and effective than others. Nevertheless, there is a common characteristic in all methods, and it is the promotion of learning; anyone can learn something with any method, or in other words, no method would have been documented and described unless it provided some benefit. For this reason, it has been believed that if it is possible to identify what is best about each method, all these "good" characteristics should be able to be combined to create a superior methodology. However, such a mixture may have some drawbacks.

\section{Eclectisism Can Be Dangerous}

The notion of eclecticism has been in vogue for a long time, and many seem to accept it without the slightest objection. Even in language teaching method's courses, it is believed that by teaching pre-service teachers the main methods that have emerged in the history of the discipline, these future teachers will be able to integrate elements from the different methods in their professional practice. At this point, we should wonder whether this is possible or desirable. If certain methods may work better in certain contexts, how can we identify the best of each of these methods? And if the identification of what is best were possible, how could we determine that the resulting eclectic mixture is really compatible or useful? Also, eclecticism could turn into some sort of uncritical argument to justify any kind of teaching practice in a classroom, be it beneficial or not, and if a teacher were to be questioned about the activities done in class, he or she could simply say "My methodology is eclectic," and those listening to this response may not be able to form clear opinions about it. 


\section{There Are No Clear Criteria to Appoint the Best Method}

Being able to measure or assess objectively the results of applying any method in comparison with another one may well be an insurmountable obstacle. For example, an experiment could be carried out in which two or more groups of students were taught with different methods to be later tested with the same exams or instruments. One could naively think that the group with the highest performance was the one following the best method, yet as mentioned previously, the context would heavily influence the effectiveness of each method. Even if it were possible to teach a group of students with a method and make them forget this experience completely in order to use a different method and compare the results, there will always be a reasonable doubt that the implementations of such methods may not have been really different. As Thornbury (2010) has stated, the different language teaching methods can be seen as different configurations of the same principles, which allows for thinking that no method can be seen as a "pure" construct or as being independent from all others. Thus, in the search for the best way to teach languages, there are some who believe it is relevant to think outside of the constructs of methods.

\section{The Post-Method Condition}

Some authors have attempted to refer to what is to expected if we go beyond language teaching methods. Richards and Rodgers (2004) suggested that in the post-method era, the language teacher should look for his or her own approach to teach languages, and they offered some general guidelines. Still, these suggestions do not provide tools or enough input for a language teacher to take the transcendental, evolutionary leap beyond methods. On the other hand, Hall (2011) argued that the line between post-method and method is a thin one, presumably because a post-method would also entail methodological and theoretical prescriptions for language teachers. Despite this, what Hall (2011) did was to criticize somebody else's ideas about the postmethod era without even proposing his own perspective about it. Nonetheless, there is an author who, through the years, has tried to problematize what path we should follow if we are to go beyond the boundaries of methods. Kumaravadivelu (2008, 2006, 2003, 1994) has referred to the "post-method condition." The post-method condition is not a new language teaching method; rather, it could be seen as another stage in the evolution of the discipline, and it consists of ten macro strategies for language teaching. Next, each of the ten 
macro strategies for language teaching ${ }^{3}$ proposed by Kumaravadivelu $(2008,2003,1994)$ will be described in a general way.

\section{Maximizing Learning Opportunities}

To foster meaningful learning, the language teacher has to provide his or her students with enough input in the classroom. Also, the teacher must try to stay away from traditional pedagogy and allow the learning experience to be more student centered. Thus, this requires planning flexibility to know the students' needs and boost their skills.

\section{Minimizing Perceptual Mismatches}

To communicate assertively, it is necessary to deliver clear messages. This should be a maxim for every teacher. Many times, there is a gap between what the teacher tries to explain and what the students ultimately understand. In sum, language teachers must become better mediators and monitor the way they communicate as they give instructions to their students. Kumaravadivelu (2008) considered that there are ten sources of possible uncertainty, namely, 1: Cognitive Mismatches, 2. Communicative Mismatches, 3, Linguistic Mismatches, 4. Pedagogic Mismatches, 5. Strategic Mismatches, 6. Cultural Mismatches, 7. Evaluative Mismatches, 8. Procedural Mismatches, 9. Instructional Mismatches, and 10. Attitudinal Mismatches.

\section{Facilitating Negotiated Interaction}

Communication, as a social phenomenon, requires that different people interact with one another in a coherent manner. In language teaching, this must be promoted in any possible ways. Not only should the teacher interact with the students, but they should interact with each other and with the teacher. It is pertinent also for teachers to see teaching and learning processes as being multidirectional. That is, the teacher is not only the one to teach, and the students the ones to learn; students can also teach their peers and their teacher. Obviously, for negotiated interaction to occur efficiently, the teacher has to be a facilitator in this process.

3 For a deeper analysis of each of the macro strategies, see Kumaravadivelu (2003). 


\section{Promoting Learner Autonomy}

In the $21^{\text {st }}$ century, students must not be seen or see themselves as passive recipients of information. Current learners must be responsible for their own learning, must learn to learn (and relearn and unlearn if necessary), must know themselves in terms of their learning styles and strategies, and above all, must be hungry to learn and not be satisfied with what they may receive in the classroom. To be able to accomplish this, teachers must guide and advise the students towards good study habits and self-knowledge. This means that at present, no one is a finished product after graduating; we will all be life-long learners.

\section{Fostering Language Awareness}

To be able to learn and ultimately use a language correctly, it is necessary to know how such a linguistic system works. Students must be helped to see which rules or principles exist in a language. It can also be added that, in the case of foreign language teaching, students must be guided to notice which similarities and differences there are between their mother tongue and the language they may be learning so that they can understand what is and what is not possible in that foreign language from a linguistic point of view.

\section{Activating Intuitive Heuristics}

Naturally, it is not feasible to learn every single existing rule or principle in a given language. It is there that intuitive heuristics comes in, the ability to infer rules and generate meaning by means of context. For this reason, efficient, autonomous language learners must develop their inferential skills to discover everything that they could not learn formally in a classroom. To deal with this macro strategy, the language teacher will have to provide the students with enough written and oral texts and guide them towards self-discovery of rules and meanings. In this sense, it can also be added that the language teacher must not forget that he or she is but a more experienced learner than his or her students. Thus, it is convenient for him or her to reflect on his or her own strategies to cope with the new and the unknown to share them with his or her students so that they can benefit from this experience. 


\section{Contextualizing Linguistic Input}

Words acquire their true meaning when they occur in a certain context. In language teaching of the $21^{\text {st }}$ century, context is crucial. The language teacher must stay away from old-fashioned practices of presenting decontextualized sentences, whose sole purpose is to illustrate a given grammatical structure. Therefore, this could be done by means of authentic materials (newspaper articles, movies, TV shows, among others) to go beyond textbooks, which all too often present artificial visions of languages.

\section{Integrating Language Skills}

Each language can be seen in terms of macro skills (listening, speaking, reading, and writing) and micro skills (pronunciation and grammar, for example). Through the years, the apparent practicality of segregating the skills of a language has predominated in the field of language teaching. However, such a separation is completely incongruous with reality. For example, you cannot speak a language without listening to it too; as well, it is very difficult to write without having read first. Each language skill is like a channel of information, so the more channels used by the teacher at a time, the better and deeper the students' learning is going to be. In sum, to foster students' better learning, the language teacher must plan activities that integrate as many language skills as possible.

\section{Ensuring Social Relevance}

The emancipatory nature of education must not be absent from the field of language teaching. The language teacher must be aware of the socio-economic and socio-political realities in which his or her educational practice takes place; he or she must empower the students for them to have a critical view of reality. For example, in the past, it was believed that the ultimate purpose of learning another language was to speak and be like a native speaker of that language, which causes students to neglect their own culture, the local, the autochthonous. Critical language learners, who are conscious about their reality, must not forget where they come from and what their identity is to be able to use two (ore more) languages successfully. 


\section{Raising Cultural Consciousness}

At present, it is necessary for students to develop global awareness. To accomplish this, we must work towards challenging the existing cultural stereotypes, discover what each culture really is, and promote understanding and tolerance among people. From the point of view of intercultural communication, it is also convenient to learn about foreign customs and identify the similarities to and differences from one's own culture since many misunderstandings emerge when one thinks that all cultures interact in the same way. Culture is seen now as yet another language skill, so to be linguistically competent, one must also be culturally competent (Celce-Murcia, 2007).

It is important to clarify at this point that all ten macro strategies for language teaching are only general action proposals for the language teacher. Kumaravadivelu (2008) has considered each of the ten macro strategies neutral both in terms of language, learning, or teaching theories and methodological principles for language teaching methods. Thus, a language teacher who wishes to use any of the macro strategies will not have to deal with theoretical or methodological prescriptions. The challenge that this language teacher will face then will be to develop his or her own micro strategies for language teaching, which will, in turn, address the macro strategies. The Post-Method Condition is an interesting and thought-provoking proposal. Nonetheless, being able to work within this paradigm entails great hurdles.

\section{Challenges Faced by the Post-Method Condition}

To be able to implement the ideas and macro strategies of the Post-Method Condition, it is necessary to surmount certain obstacles. The first of them is teacher education (Akbari, 2008). Courses that cover topics related to language teaching methodologies must be refocused to change the ingrained views of why the different language teaching methods proposed throughout history must be studied in order to avoid the misunderstandings of eclecticism. Maybe, because of this and political, social, and economic reasons, it has been reported that it is not feasible to implement post-method pedagogy (Khatib \& Fathi, 2014; Khatib \& Fat'hi, 2012). Moreover, to be able to train teachers at present, the use of textbooks may be a limitation since as considered by McMorrow (2007), they may favor neocolonialist practices over local knowledge and resources. Another area of criticism towards the Post-Method Condition is that, according 
to Hashemi (2011), it is but the proposal of another language teaching method or a mere reinterpretation of Communicative Language Teaching (CLT). Finally, one more challenge for the Post-Method Condition is the amount of responsibility resting on the teacher's shoulders (Kamali, 2014), which adds to an already long list of duties in the practice of a language teacher. Anyway, all these challenges may be the reasons why teaching tools and textbooks are overused at present as will be described below.

\section{A Different View in an Era of Abundance: Dogma}

In the 21 st century, the amount of teaching tools available can be overwhelming (books, videos, audio recordings, mobile apps, learning platforms on the Internet, smart boards, interactive software, among others). Such abundance causes some teachers to fall into a sort of gluttony of teaching tools and to believe that these resources must be used just because they are available without thinking of what added value they may provide in teaching and learning processes. Many times, the obtained results are lessons overloaded with materials which are not properly exploited. In the era of abundance, Thornbury $(2005,2000)$ has suggested a minimalist proposal when thinking that language lessons have been kidnapped by such great variety of different teaching resources and by a compulsive obsession with grammar. On the other hand, before attempting to describe this methodological proposal, it is necessary to clarify, as Thornbury himself $(2010,2000)$ has done, that his idea is not a new language teaching method. It could be seen as a philosophy or a paradigm more properly.

Thornbury's attention (2000) was attracted towards a group of Danish movie makers who got together and came up with what he described as a "vow of chastity" to get rid of the artificiality of special effects and sets created for movies. When analyzing the ideas from the group Dogme 95, Thornbury (2000) considered that they could be extrapolated to language teaching to try to do more with fewer resources; from there, Thornbury (2000) coined the term "dogma." In Thornbury's minimalist view $(2005,2000)$, the teacher and the students are the main resources to learn a language. This does not mean, however, that we must dispense with every published or produced language teaching resource. Rather, the language teaching tools to be used in class must be useful beyond their being appealing or new; they must be chosen carefully and critically, and they must demonstrate beyond the shadow of a doubt that they produce better results than traditional means. 
In this view, all the participants of the teaching and learning process must be autonomous and must make the lessons of a course their own and tailor them according to their needs and interests; learning must be more experiential and experimental. Hence, communication among all the participants is crucial (Thornbury, 2005) to obtain the intended results. In this sense, Thornbury (2005) warned that "dogma" shares many similarities with such approaches as those of humanist education and critical pedagogy. Once more, none of this sounds seemingly innovative. Nonetheless, at present, this is what we all need. New technologies make our lives easier; they are useful, yet they may alienate us, divest us of our humanity, of our solidarity, and of our criticalness. What makes us human must not be left behind in any educational contexts. Education must never be seen as something mechanical or generic, in which students go through an assembly line that shapes them in the exact same way. Unfortunately, at present, publishers very often deprive teachers from pedagogical freedom and flexibility.

\section{A Very Current Warning: Texbook-Defined Practice}

There are many who see teaching as something simple and belittle the role that teachers may play in teaching and learning processes. For this reason, there is the erroneous assumption that there are teaching formulas that anyone can follow to obtain the same results. Richards (2001, p. 169) has argued that "[t]he assumption that underlies general, all-purpose methods is hence essentially this: Teachers cannot be trusted to teach well." Therefore, teachers are to follow recipes prescribed by "experts" so as not to make mistakes in their professional practice. In like manner, there is a current and even more pernicious phenomenon: textbook-defined practice (Akbari, 2008). Now, it is increasingly common to see that in different educational institutions, books become courses or courses become books (whatever happens first). Publishers come and offer their books series, and these are adopted without major selection criteria; what happens next is that syllabi are edited, and the contents are susbtituted by those of the table of contents of the books. There may be nothing more limiting for a teacher's job than this colonizing pseudo-curricular phenomenon, in which teachers are forced to follow a book that has been prescribed by people who probably do not know the existing curriculum designs in a country or at a school, let alone the socio-economic contexts in which the books are going to be used. 
It is also worrying that many teachers see those books as allies, especially when they are thick because that way, they can simply follow them in class without having to plan lessons or prepare many (or any) teaching materials. These teachers' complaint is big when in a school or language program, "simple" or "thin" books are used since that takes them out of their comfort zone and forces them complement the books with additional materials. It is sad that they do not see this as an opportunity. That a teacher is given a simple or thin book is the greatest sign of respect that he or she can receive as a professional because that way, this teacher can allot more time to cater for his or her students' real needs. Textbooks are generic, global, and idealized proposals. A critical teacher should be aware that the true challenge lies in taking this proposal, adapting it, and turning it into something local, specific, and emancipatory.

\section{Conclusion}

The field of language teaching has a long (but not necessarily innovative) history, and as has been described in this essay, it has not necessarily had an evolutionary development, going from nothing to something. This means that in language teaching method courses, even if we draw a timeline going from the oldest to the most modern method, the progress of the field has not been linear; rather, it has been a spiral of constant reconfiguration. In this sense, as suggested by the title of this paper, there is nothing new under the sun. It is possible to identify nine spectra of methodological possibilities in practically all of the language teaching methods. Even so, knowing the scopes of each of these dimensions may provide inputs for lesson planning.

On the other hand, the search for the best language teaching method may turn into a fruitless attempt until each teacher realizes that what really matters is the commitment and effort put into the classroom on a daily basis. Thence, such proposals as the PostMethod Condition or Dogma may perhaps emerge, which, in spite of their challenges, seek to empower language teachers in their professional practice. Finally, attention has been drawn towards the least promising path in language teaching, textbook-defined practice and its implications.

At this post-modern moment of language teaching, it is up to every teacher to reflect upon the path followed in his or her practice and decide whether it is worth going forward or whether it is worth questioning what they have done up to now and re-creating themselves as professionals. In the $21^{\text {st }}$ century, no teacher must stop 
learning, and they must research and reflect upon their professional practice to make any necessary changes that may benefit students and ultimately contribute to social development. Such decisions may entail fighting inefficient education and political systems and dealing with various limitations. It is up to every teacher to accept the challenge or not.

\section{References}

Akbari, R. (2008). Postmethod discourse and practice. TESOL Quarterly, 42(4), 641-652.

Celce-Murcia, M. (2007). Rethinking the role of communicative competence in language teaching. In E. Alcón \& M. P. Safont (Eds.), Intercultural Language Use and Language Learning (pp. 41-57). Dordrecht: Springer.

Hall, G. (2011). Exploring English language teaching: Language in action. New York: Routledge.

Hashemi, S. (2011). (Post)-Methodism: Possibility of the impossible? Journal of Language Teaching and Research, 2(1), 137-145. doi:10.4304/j1tr.2.1.137-145

Kamali, J. (2014). Postmethod survival. Procedia-Social and Behavioral Sciences, 98, 824-829.

Khatib, M., \& Fathi, J. (2014). The investigation of the perspective of Iranian EFL domain experts on post-method pedagogy: A delphi technique. The Journal of Teaching Language Skills, 6(3), 101-124.

Khatib, M., \& Fat'hi, J. (2012). Postmethod pedagogy and ELT teachers. Journal of Academic and Applied Studies, 2(2), 2229.

Kumaravadivelu, B. (2008). Understanding Language Teaching: From Method to Postmethod. New Jersey: Lawrence Erlbaum Associates.

Kumaravadivelu, B. (2006). TESOL methods: Changing tracks, challenging trends. TESOL Quarterly, 40(1), 59-81.

Kumaravadivelu, B. (2003). Beyond methods: Macrostrategies for language teaching. New Haven: Yale University Press.

Kumaravadivelu, B. (1994). The post method condition: (E)merging strategies for second/foreign language teaching. TESOL Quarterly, 28(1), 27-48.

McMorrow, M. (2007). Teacher education in the postmethods era. ELT Journal, 61(4), 375-377.

Prabhu, N. S. (1990). There is no best method-Why? TESOL 
Quarterly, 24(2), 161-176.

Richards, J. C. (2001). Beyond methods. In C. N. Candlin \& N. Mercer (Eds.), English language teaching in its social context: A reader (pp. 167-179). New York: Routlege.

Richards, J. C., \& Rodgers, T. (2004). Approaches and methods in language teaching (2nd Ed.). New York: Cambridge University Press.

Thornbury, S. (2010). The secret history of methods. Retrieved from https:/www.youtube.com/watch?v=L2q9B2BEV2U

Thorrnbury, S. (2005). Dogme: Dancing in the dark. Folio 9(2), 3-5.

Thorbury, S. (2000). A dogma for EFL. IATEFL Issues, 153, 2. 